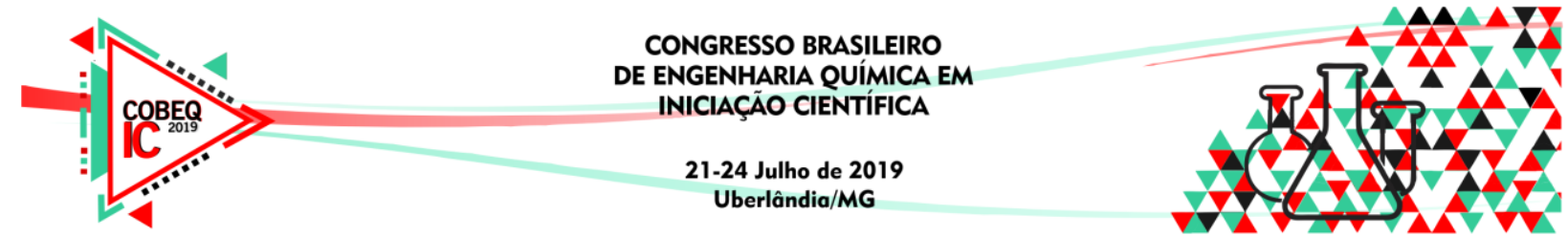

\title{
ANÁLISE COMPARATIVA E CARACTERIZAÇÃO DO BIODIESEL DE ÓLEO DE SOJA E BANHA DE PORCO EM SÍNTESE POR AQUECIMENTO E AGITAÇÃO CONSTANTE
}

\author{
G. G. SILVA ${ }^{1}$, L. H. J. da $\operatorname{COSTA}^{1}$, L. M. MELO ${ }^{1}$; N. S. OLIVEIRA ${ }^{1}$; A. S. CRUVINEL ${ }^{2}$ \\ ${ }^{1}$ Centro Universitário de Patos de Minas, Faculdade de Engenharia Química \\ E-mail para contato: gustavo.gs.98@ hotmail.com \\ ${ }^{2}$ Centro Universitário de Patos de Minas, Faculdade de Engenharia Química \\ E-mail para contato: abelsc@unipam.edu.br
}

\begin{abstract}
RESUMO - O esgotamento de combustiveis fósseis representa o maior gargalo na atual configuração da matriz energética mundial, indicando como alternativa para esse problema, a substituição pelos biocombustíveis. O presente trabalho teve como objetivo realizar a síntese de um biodiesel a partir da mistura de óleo de soja e gordura suína, com uma proporção de 70:30 respectivamente. A síntese foi obtida por duas rotas: metílica e etílica, nas duas rotas foi utilizado $\mathrm{KOH}$ (hidróxido de potássio) para atuar como catalizador no processo de transesterificação sob agitação constante, pressão atmosférica e temperatura constante de $70^{\circ} \mathrm{C}$, tendo consequentemente à sua decantação, e extração do glicerol decantado, a realização de uma lavagem com $\mathrm{HCl}$ (ácido clorídrico) e lavagem com água destilada à $60^{\circ} \mathrm{C}$ para a remoção da glicerina e do ácido de lavagem. Pórem somente na rota metílica o biodiesel foi transesterificado, logo o biodiesel sintetizado foi direcionado a testes para físico-químicos e qualiquantitativos para sua caracterização e verificação de viabilidade de sua produção e utulização. O rendimento observado foi de $74,31 \%$ com um total de $281,79 \mathrm{~g}$ de biodiesel produzido, e $62,65 \mathrm{~g}$ de glicerina residual. $\mathrm{O}$ potencial hidrogeniônico se mostrou ácido com 3,16. A densidade foi de $0,96 \mathrm{~g} / \mathrm{mL}$. O resultado da condutividade elétrica foi $0,09 \mu . \mathrm{S} / \mathrm{cm}$ e o teste de inflamabilidade se mostrou positivo. Diante disso, a síntese do biodiesel obtido a partir da rota metílica apresentou um coeficiente de rendimento muito atrativo, pórem, a necessidade de realização de mais testes físico-químicos mostra-se presente, logo que o biodiesel é uma fonte renovável e de baixo custo.
\end{abstract}

\section{INTRODUÇÃO}

Há alguns anos a literatura apresenta discussões sobre o esgotamento de combustíveis fósseis, amplamente usados atualmente, e logo surge a pergunta: "Qual será a alternativa para manter todo esse ritmo? ". Uma das alternativas são os Biocombustíveis. Segundo a ANP (Agência Nacional do Petróleo), biocombustíveis são derivados de biomassas renováveis que podem substituir combustíveis derivados do petróleo ou gás natural em motores à combustão ou em outros tipos de geração de energia. 


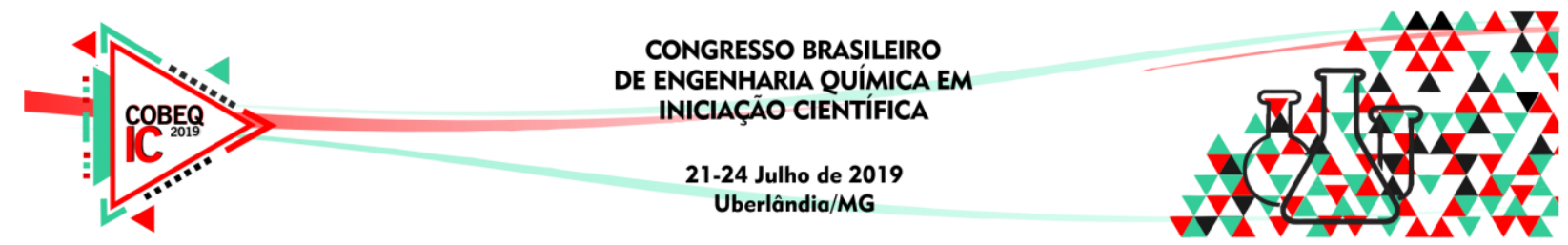

O primeiro biocombustível no Brasil foi o álcool proveniente da cana-de-açúcar, surgiu por volta de 1920, porém somente em 1975 após o Proálcool (Programa Nacional do álcool) que teve por inciativa oferecer incentivos fiscais e empréstimos com juros abaixo da taxa a produtores de cana-de-açúcar e indústrias automobilísticas para produzirem carro movido a álcool ajudando o país a sair de uma crise petrolífera, e logo na primeira década esses veículos movidos a álcool se tornaram $60 \%$ do cenário brasileiro aumentando assim a venda do álcool (Leite e Leal, 2007).

O biodiesel, que é um tipo de biocombustível, é sintetizado através de fontes vegetais misturadas com etanol, por meio de transesterificação, é totalmente limpo, orgânico e renovável. O biodiesel tem vantagens ecológicas, pois não contém óxido de enxofre (causador da chuva ácida) e também controla o efeito estufa; vantagens econômicas e financeiras pois seu custo é menor, gera empregos para produtores rurais e com sua síntese cria-se glicerina que é matéria-prima para outras industrias (Rathmann et al, 2005).

Segundo Abreu et al (2008) o biodiesel é produzido das mais diversas matérias-primas, por exemplo, plantas oleaginosas, como: milho, soja, girassol. Mas também pode ser utilizada gordura animal, como: sebo bovino, gordura suína e gordura de aves. O uso desses resíduos gordurosos reduz o impacto ambiental, evitando descarte inadequado, além de ser um atrativo econômico.

De acordo com a EMBRAPA são produzidas anualmente 355 mil toneladas de graxa suína, a partir de abatedouros e maior parte é disposta à produção de ração animal. Um suíno, em média produz 8 quilos de banha, e cada quilo pode ser convertido em $750 \mathrm{ml}$ de biodiesel. Segundo Ribeiro (2010), a gordura de porco é composta por ácidos graxos saturados e insaturados.

Para que ocorra o processo da obtenção do biodiesel é necessário que a gordura esteja livre de ácidos graxos livres e de umidade, pois a água pode formar reações paralelas de saponificação e após feita a secagem é indicado que ocorra uma neutralização com solução básica. Para obtenção do biocombustível indica-se a reação da matéria-prima com álcool, catalisada por um agente ácido. Milli (2011) afirma que entre a mistura de óleos vegetais e gorduras animais também são formadas as reações de transesterificação.

Diante disso, o objetivo deste trabalho é a obtenção do biodiesel a partir da mistura da gordura suína e óleo de soja, assim como realizar análises qualiquantitativas e estudar qual o potencial e viabilidade do biodiesel produzido.

\section{METODOLOGIA}

O seguinte trabalho teve início com a síntese do biocombustível no Laboratório de Química Orgânica situado no bloco $M$ do Centro Universitário de Patos de Minas UNIPAM. Realizou-se a síntese na proporção de 70:30 Óleo/Gordura, após os respectivos cálculos estequiométricos, utilizou-se 90 gramas de gordura de porco fornecida pela Empresa Kallas e 210 gramas de óleo de soja tipo 1 fornecida pela Great Value. Para rota metílica foi utilizado $100 \mathrm{~mL}$ de metanol. 


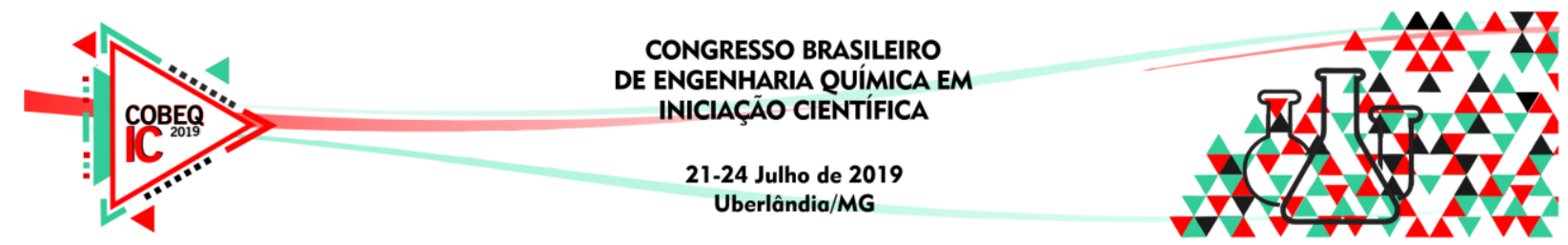

Para o início da síntese adicionou-se 3 gramas de $\mathrm{KOH}$ (hidróxido de potássio) para atuar como catalizador e manteve em agitamento constante no agitador magnético IKA CMAG HS4 por cerca de duas horas à $70^{\circ} \mathrm{C}$. Após o tempo de reação os experimentos foram levados para funis de separação e deixados em repouso para decantar a glicerina que se forma. As soluções são lavadas com $100 \mathrm{~mL}$ de $\mathrm{HCl}$ (ácido clorídrico) $1 \mathrm{~mol} / \mathrm{L}$ e duas vezes com água destilada à $60^{\circ} \mathrm{C}$ para a retirada total da glicerina e para retirar o ácido de lavagem.

Após todo glicerol ser retirado, foram guardados a glicerina, as águas de lavagem e os biocombustíveis em potes devidamente rotulados para posterior qualiquantificação.

\subsection{Testes Qualiquantitativos}

Para a qualificação e quantificação do biocombustível produzido foram executados alguns testes. Primeiramente foram realizados cálculos de quantificação para o rendimento e produtividade a partir da massa final de biocombustível precisados na Balança Marte. Logo após iniciou-se os testes qualitativos.

- Determinação do $p \mathrm{H}$ : A aferição do $p \mathrm{H}$ foi obtida através do aparelho $p \mathrm{Hmetro} \mathrm{MS}$ Tecnopom Instrumentação MPa 210.

- Determinação da densidade: A densidade é dada pela Equação 1, e é obtida através da razão entre massa e volume utilizando o picnômetro de $50 \mathrm{~mL}$.

$$
D=\frac{m}{v}
$$

Sendo: D: densidade, m: massa, v: volume.

- Determinação da condutividade: Aferiu-se a condutividade através do aparelho condutivímetro Alfa Mare MS Tecnopom.

- Determinação da acidez: A acidez é dada pela Equação 2, e foi obtida a partir de uma titulação em triplicata onde, na bureta utiliza-se $\mathrm{KOH}$ e isopropanol, no erlenmeyer utiliza-se 10 gramas da amostra de biocombustível com 75 mL Etanol/Água (60:40) e indicador azul de bromotimol ou vermelho de metila.

$$
\frac{\text { Volume da base } * \text { concentração } \mathrm{KOH} *\left(\frac{\text { massamolar }}{2}\right)}{\text { volume amostra utilizada }} * 100
$$

- Teste da inflamabilidade: Em um cadinho adiciona-se um algodão embebido com biocombustível e acende uma chama próximo, onde espera-se que entre em combustão. 


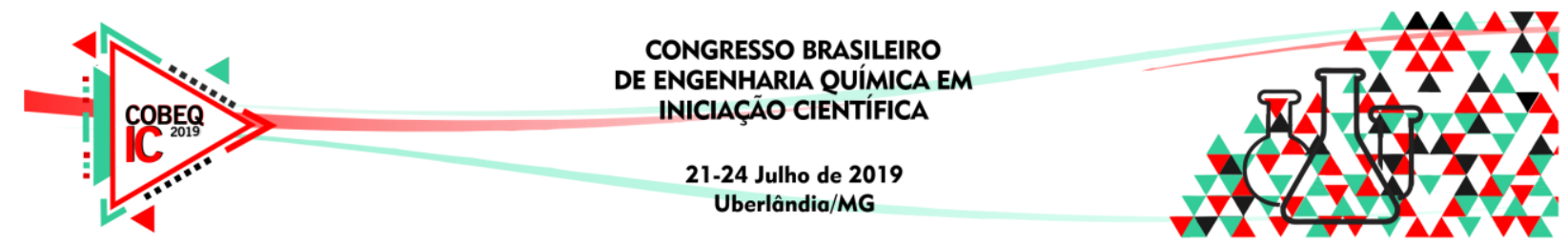

\section{RESULTADOS E DISCUSSÕES}

A síntese do biodiesel pela rota metílica foi concluída com sucesso, foi observada a diluição do catalizador, e a mistura óleo/gordura/álcool ficou homogênea, tornando o processo viável. O método de aquecimento foi realizado sob agitação constante.

A Tabela 2 mostra os resultados de $\mathrm{pH}$, densidade, índice de acidez e condutividade elétrica, realizados no biocombustível produzido pela rota metílica.

Tabela 2 - Resultados de pH, densidade, índice de acidez e condutividade elétrica

\begin{tabular}{ccc}
\hline TESTES & \multicolumn{2}{c}{ RESULTADOS } \\
\hline$p \mathrm{H}$ & 3,16 & $6,00(\mathrm{Dib}, 2010)$ \\
Densidade $(\mathrm{g} / \mathrm{L})$ & 0,96 & $0,88(\mathrm{Cunha}, 2008)$ \\
Índice de Acidez $(\mathrm{mg} / \mathrm{L})$ & 0,027 & $0,010($ Cunha, 2008) \\
Condutividade elétrica $(\mu \mathrm{S} / \mathrm{cm})$ & 0,09 & $2,5 \mathrm{e}-7$ (ANP) \\
\hline
\end{tabular}

No término do processo obteve-se $74,31 \%$ de rendimento do biodiesel próximo a uma média estimada pelo biodiesel e produtividade de $281,79 \mathrm{~g}$. O resultado final de glicerol foi de 62,65g. O pH aferido foi de 3,16 sendo um pouco mais ácido que o encontrado para comparação, que pode ser justificado pelo fato de que na síntese de Dib (2010) foi usado $\mathrm{NaOH}$ (hidróxido de sódio) como catalisador. O valor da densidade obtido foi de 0,96 encontra-se elevado ao se comparar com as referências utilizadas, essa divergência de resultado ocorreu devido ao método utilizado para determinação, do clima predominante no ambiente e local da síntese do biodiesel. O índice de acidez observado no biodiesel produzido tem pouca divergência quando comparado com o valor estipulado como aceitável pela ANP. Em observância ao método e tipo de catalizador utilizado, o resultante de $0,09 \mu \mathrm{S} / \mathrm{cm}$ foi superior e essa diferença pode ser explicada devido ao tipo de matéria-prima utilizada, considerando que o índice de acidez resultante do biodiesel sofre influência direta da base de óleo vegetal utilizada no estudo. O teste de inflamabilidade foi identificado como positivo, observando a queima completa do biodiesel resultando, então, na ausência de resíduos.

\section{CONCLUSÃO}

Conforme o objetivo proposto, a partir da síntese do biodiesel de óleo de soja juntamente com a gordura suína se mostrou satisfatória de acordo com os resultados obtidos no $p \mathrm{H}$, na densidade, no índice de acidez e na condutividade elétrica pela rota metílica. No entanto, seria necessário realizar outros testes físico-químicos nesse biodiesel além de sua mistura com diesel e aplicação em um motor adequado, a fim de que seja concluída sua eficiência e possivelmente sua utilização, já que é uma fonte renovável e de baixo custo.

\section{REFERENCIAS}

ABREU, Y. V. de; OLIVEIRA, H. R. de; LEAL, J. E. C. Biodiesel no Brasil em Três Hiatos: Selo Combustível Social, Empresas e Leilões. 2005 a 2012. EUMED. NET, 2012.

ANP. Agência Nacional do Petróleo, Gás Natural e Biocombustíveis. Disponível em:< http://www.anp.gov.br/producao-de-biocombustiveis >. Acesso: 21 out. 2018. 


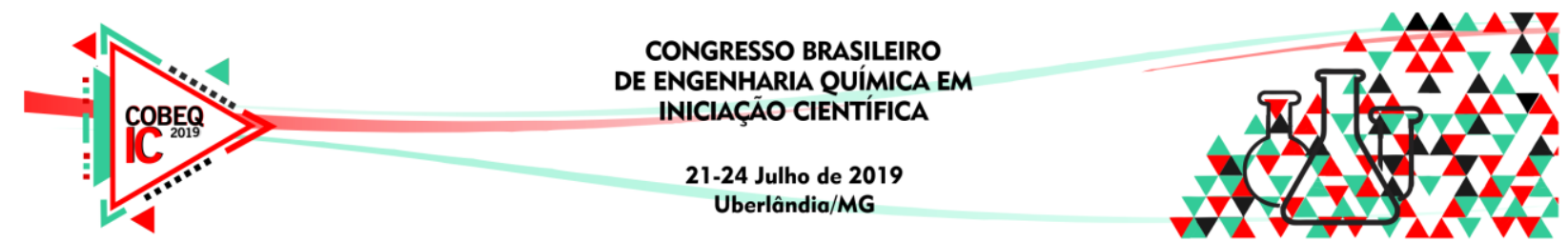

CUNHA, M. da E. Caracterização de Biodiesel Produzido com Misturas Binárias de Sebo Bovino, Óleo de Frango e Óleo de Soja. 2008. 86 f. 2008. Tese de Doutorado. Dissertação (Mestrado em Química) -, Universidade Federal do Rio Grande do Sul, Instituto de Química, Porto Alegre.

DIB, Fernando Henrique. Produção de biodiesel a partir de óleo residual reciclado e realização de testes comparativos com outros tipos de biodiesel e proporções de mistura em um moto-gerador. 2010.

EMBRAPA. Empresa Brasileira de Pesquisa Agropecuária. Disponível em:< http://www.agencia.cnptia.embrapa.br/gestor/agroenergia/arvore/CONT000fj1 om7kf02 wyiv802hvm3jholyoom.html>. Acesso: 10 set. 2018.

LEITE, R. C. de C.; LEAL, M. R. LV. O biocombustível no Brasil. Novos estudos CEBRAP, n. 78, p. 15-21, 2007.

MILLI, B. B.et al. Produção de biodiesel a partir da mistura de sebo bovino com óleo vegetal. Enciclopédia Biosfera, v.7, n.12; p.1-26, 2011.

RATHMANN, R.; BENEDETTI, O.; PLÁ, J. A.; PADULA, Antonio Domingos. Biodiesel: Uma alternativa estratégica na matriz energética brasileira? In: II Seminário de Gestão de Negócios. Curitiba: UNIFAE, 2005.

RIBEIRO, T. C. Síntese de Insumos Químicos a partir de Biodiesel Produzido pela Transesterificação de Gordura Animal Dissertação de Mestrado - Universidade Estadual de Campinas, Faculdade de Engenharia Química, 2010. 